\title{
Vasculites dos médios e grandes vasos *
}

\author{
Medium and large vessel vasculitis
}

\author{
Hebert Roberto Clivati Brandt ${ }^{1}$ \\ Neusa Yuriko Sakai Valente ${ }^{3}$ \\ Paulo Ricardo Criado 5
}

\author{
Marcelo Arnone ${ }^{2}$ \\ Mirian Nacagami Sotto ${ }^{4}$
}

\begin{abstract}
Resumo: As vasculites são constituídas por um grande grupo de síndromes caracterizadas por inflamação e necrose da parede dos vasos sangüíneos, resultando em estreitamento ou oclusão do lúmen. A distribuição dos vasos envolvidos varia consideravelmente e serve de base para a classificação das síndromes vasculíticas: grandes vasos (arterite de Takayasu, arterite temporal); pequenos e médios vasos (poliarterite nodosa, síndrome de Churg-Strauss, granulomatose de Wegener, vasculites nas doenças reumáticas); e pequenos vasos (vasculite de hipersensibilidade, púrpura de Henoch-Schonlein, poliangeíte microscópica, crioglobulinemia). Este artigo revisa as vasculites dos médios e grandes vasos e opções terapêuticas atuais; além de oferecer orientação sobre abordagem diagnóstica e tratamento dos pacientes com suspeita de vasculite cutânea.

Palavras-chave: Anticorpos anticitoplasma de neutrófilos; Arterite de células gigantes; Arterite de Takayasu; Doenças reumáticas; Granulomatose de Wegener; Poliarterite nodosa; Púrpura; Síndrome de Churg-Strauss; Vasculite; Vasculite alérgica cutânea
\end{abstract}

\begin{abstract}
Vasculitis comprises a broad group of syndromes characterized by inflammation and necrosis on the walls of blood vessels, resulting in narrowing or occlusion of the lumen. The distribution of involved blood vessel varies considerably and serves as the basis for one classification of vasculitic syndromes: large vessels (Takayasu arteritis, giant cell arteritis); medium and small muscular arteries (polyarteritis nodosa, Churg-Strauss syndrome, Wegener's granulomatosis, vasculitis in rheumatic diseases); and small vessels ("hypersensitivity" vasculitis, Henoch-Schonlein purpura, microscopic polyangiitis, cryoglobulinemia). This article reviews medium and large vessel vasculitis and current treatment options; it also presents a comprehensive approach to diagnosing and treating patients with suspected cutaneous vasculitis.

Keywords: Antibodies, antineutrophil cytoplasmic; Churg-Strauss syndrome; Giant cell arteritis; Polyarteritis nodosa; Purpura; Rheumatic diseases; Takayasu arteritis; Vasculitis; Vasculitis, allergic cutaneous;

Wegener granulomatosis
\end{abstract}

Recebido em 20.06.2008.

Aprovado pelo Conselho Consultivo e aceito para publicação em 26.12.08

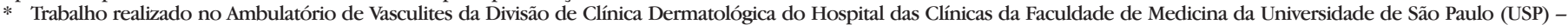
São Paulo (SP), Brasil.

Conflito de interesse: Nenhum / Conflict of interest: None

Suporte financeiro: Nenhum / Financial funding: None

Médico preceptor do Departamento de Dermatologia da Faculdade de Medicina da Universidade de São Paulo (USP) - São Paulo (SP), Brasil.

Médico dermatologista, mestre em Ciências, área de concentração dermatologia pela FMUSP, assistente da Divisão de Clínica Dermatológica do Hospital das Clínicas da Faculdade de Medicina da Universidade de São Paulo (USP) - São Paulo (SP), Brasil.

Professora doutora, dermatologista e pesquisadora do Laboratório de Investigação Médica, LIM 53, do Hospital das Clínicas da Faculdade de Medicina da Universidade de São Paulo (USP) - São Paulo (SP), Brasil.

Professora-associada do Departamento de Dermatologia da Faculdade de Medicina da Universidade de São Paulo e patologista do Laboratório de Histopatologia da Divisão de Clínica Dermatológica do Hospital das Clínicas da Faculdade de Medicina da Universidade de São Paulo (USP) - São Paulo (SP), Brasil.

Médico dermatologista, doutor em Ciências, área de concentração dermatologia pela FMUSP, assistente da Divisão de Clínica Dermatológica e pesquisador do Laboratório de Investigação Médica, LIM 53, do Hospital das Clínicas da Faculdade de Medicina da Universidade de São Paulo, responsável pelo Ambulatório de Vasculites do HC-FMUSP) - São Paulo (SP), Brasil. 


\section{INTRODUÇÃO}

As vasculites predominantemente dos pequenos vasos, em particular a vasculite cutânea dos pequenos vasos (VCPV), constituem as formas mais comuns de vasculites que se apresentam aos dermatologistas. No entanto, a própria púrpura palpável pode apresentar-se dentro do espectro de manifestações clínicas de vasculites dos médios vasos, as quais mais freqüentemente são direcionadas aos demais especialistas, como reumatologistas, pneumologistas e nefrologistas, devido a seu acometimento multissistêmico. Em artigo recente da Educação Médica Continuada dos Anais Brasileiros de Dermatologia, revisaram-se as vasculites predominantemente dos pequenos vasos. Neste artigo de revisão o escopo é dirigido às vasculites dos médios e grandes vasos.

\section{1 - PREDOMINANTEMENTE DE VASOS DE MÉDIO CALIBRE}

Acometem os vasos da pele de 50 a $100 \mu \mathrm{m}$ de diâmetro na junção dermo-hipodérmica.

\section{Poliarterite nodosa}

A poliarterite nodosa pode apresentar manisfestações sistêmicas e cutâneas. É dividida em clássica e cutânea.

\section{1a. Poliarterite nodosa clássica}

Identificada como PAN clássica, é doença multissistêmica que pode provocar grande morbidade. As lesões cutâneas ocorrem em proporção de apenas 20 a 50\% dos pacientes, sendo a púrpura palpável sua manifestação mais comum. As lesões cutâneas sugestivas de envolvimento dos grandes vasos manifestam-se como úlceras cutâneas grandes ou "pontuadas" e gangrena digital. ${ }^{1-4}$

São características da poliarterite nodosa clássica: doença multissistêmica; o fato de acometer mais homens; qualquer idade; sintomas constitucionais como febre, mal-estar, perda de peso, artralgia; a vasculite determina sintomas e sinais como: fadiga muscular, dor abdominal, mononeurite múltipla, hipertensão arterial, orquite (mais comum quando associada à infecção pelo HBV), insuficiência cardíaca congestiva; tem o vírus da hepatite B como causa em percentual que varia de $5 \%$ a 7\%; há múltiplas dilatações nas artérias de médio calibre dos rins, fígado e outros órgãos internos. Essa dilatação não é patognomônica, ocorrendo também em outras doenças; manifestações cutâneas em percentual que varia de $20 \%$ a $50 \%$ dos casos, principalmente púrpura palpável, podendo ocorrer também outras, como livedo reticular, úlceras grandes, nódulos subcutâneos e, raramente, infarto digital. ${ }^{1,2,4-6}$

\section{1b. Poliarterite nodosa cutânea}

$\mathrm{Na}$ PAN cutânea as lesões surgem como nódulos dérmicos ou subcutâneos, especialmente dispostos na porção inferior das pernas, próximo da região maleolar, podendo ascender às coxas e nádegas, e, eventualmente, a mãos e pés (Figura 1). Esses nódulos podem ulcerar (Figura 2) e, ao remitir, deixam pigmentação livedóide tipo "poeira estelar" (Figura 1) ou cicatrizes estelares marfíneas tipo atrofia branca. Nas crianças é observada gangrena digital. Neuropatia periférica ocorre em $20 \%$ dos doentes, do tipo mononeurite múltipla. Em alguns doentes observam-se apenas livedo racemoso extenso e neuropatia periférica (Figura 3). A PAN cutânea está associada à infecção estreptocócica (especialmente em crianças), ao parvovírus B19, HIV, vírus da hepatite B, tuberculose, além de doença intestinal inflamatória e trombose da veia cava inferior.

São descritos, em séries estudadas, cinco fatores associados com maior mortalidade entre os doentes: a creatinina $>1,58 \mathrm{mg} / \mathrm{dl}$; proteinúria $>1 \mathrm{~g} / \mathrm{dia}$; acometimento do trato gastrointestinal; acometimento do sistema nervoso central; cardiomiopatia.

Os autores observaram a sobrevida em cinco anos dos doentes de acordo com a presença das manifestações acima relacionadas: nenhum fator $(88 \%)$, um fator presente (74\%), dois ou mais fatores presentes (54\%)., ${ }^{1,4-6}$

Observa-se no material de biópsia arterite inflamatória necrotizante e obliterativa, acometendo artérias de pequeno e médio calibre, com paniculite focal. Podem surgir aneurismas. Os ramos arteriais mais afetados podem romper, ocasionando trombose luminal e obliteração, com isquemia distal e necrose (Figura 4).

\section{2 - VASOS DE MÉdIO CALIBRE E PEQUENOS VASOS}

As vasculites dos vasos de médio calibre e pequenos vasos podem apresentar-se nas seguintes formas:

\subsection{Associadas ao Anca ("pauciimunes")}

Além dos fatores etiopatogênicos envolvidos nas VCPV, que também se aplicam às vasculites necrotizantes
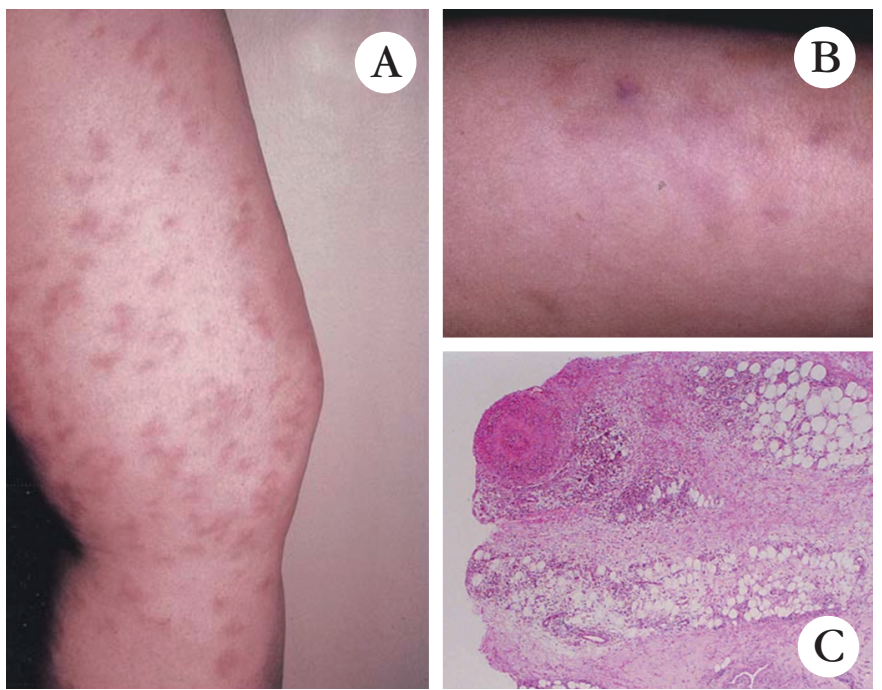

Figura 1: A e B - Nódulos dérmicos e subcutâneos dispostos nos membros, associados à pigmentação livedóide tipo "poeira estelar"

C - Comprometimento de artéria de septo da hipoderme. HE, 100x 
dos médios e grandes vasos, atualmente o envolvimento dos superantígenos têm sido demonstrado nesse grupo de vasculites. Os superantígenos (SAgs) são peptídeos capazes de induzir vários processos imunológicos e dempenham papel importante na manutenção do estado inflamatório. Os SAgs ligam-se a proteínas que não são normalmente processadas pelas células apresentadoras de antígenos e a moléculas do MHC de classe II localizadas nas regiões não polimórficas. Essas regiões são diferentes dos locais de ligação dos antígenos imunologicamente processados. Dessa forma, os SAgs podem interagir com grande número de linfócitos $\mathrm{T}$ que não necessitam apresentar um receptor de célula $\mathrm{T}$ antígenoespecífico. A maioria dos SAgs é molécula de origem microbiana. Estudos têm demonstrado que na granulomatose de Wegener, síndrome de Kawasaki, arterite de Takayasu, poliangeíte microscópica e arterite de células gigantes, os SAgs do $S$. aureus e em menor freqüência do $S$. pyogenes podem perpetuar o processo de vasculite nos pacientes que são colonizados ou são portadores nasais dessas bactérias. ${ }^{7 \cdot 10}$

O Anca está presente em $5 \%$ da população normal. Na IFI, há três padrões de Anca: ${ }^{9}{ }^{10}$ citoplasmático (cAnca), perinuclear (p- Anca) e o padrão atípico (a- Anca).

Os pacientes geralmente expressam apenas um padrão, sendo c- Anca ou p- Anca os mais comuns. Se forem expressos concomitantemente são sugestivos de vasculite induzida por droga. O p- Anca é menos específico, ocorrendo com maior freqüência na poliangeíte microscópica, síndrome de Churg-Strauss, glomerulonefrite necrotizante crescente idiopática e vasculite induzidas por droga. O c- Anca é mais freqüente e específico na granulomatose de Wegener. ${ }^{2,4,6}$

Vasculite dos pequenos vasos associadas ao Anca (VPV- Anca) apresentam sintomas sobrepostos com as diferentes vasculites a eles associadas. Hemorragia pul-

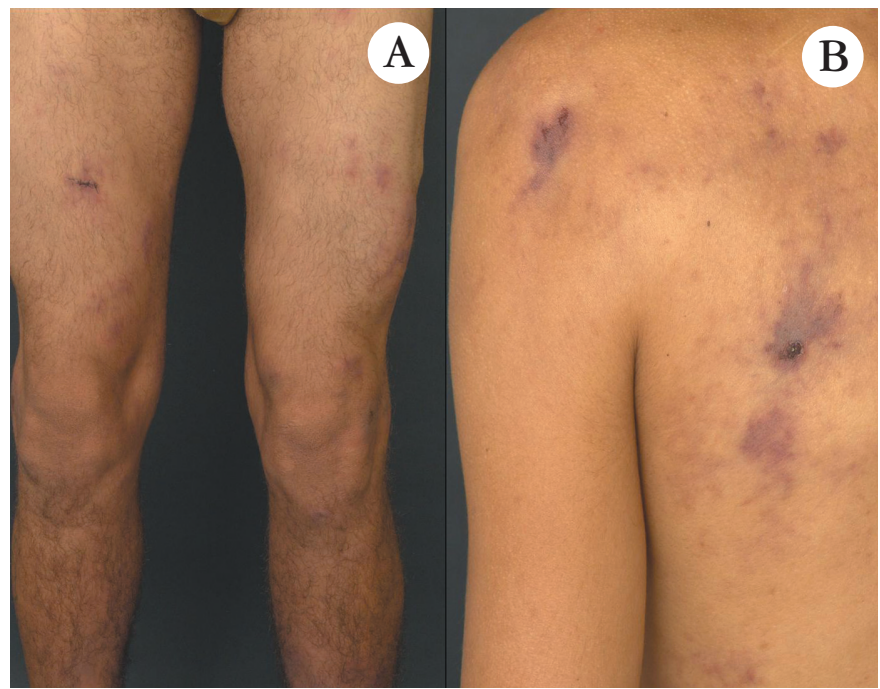

Figura 2: A - Nódulos dérmicos nos membros inferiores B - Nódulos ulcerados com superfície purpúrica associados à pigmentação livedóide no dorso e membro superior monar e glomerulonefrite necrotizante em crescente (GNNC) podem estar associadas, constituindo a "síndrome pulmonar-renal". As vasculites dos pequenos vasos associadas ao Anca são denominadas pauciimunes, uma vez que a imunofluorescência direta não demonstra presença de depósitos de imunocomplexos na parede ou ao redor dos vasos ou deles revela escassas evidências. O Anca deve ser pesquisado à suspeita de VPV- Anca, nas seguintes situações clínicas: ${ }^{2,4,6,11}$ presença de hemorragia pulmonar; glomerulonefrite; otite ou sinusite de longa evolução; presença de massa ou tumoração retroorbitária (suspeitar de GW); qualquer vasculite sistêmica com acometimento de múltiplos órgãos.

\subsubsection{Poliangeíte microscópica}

Constitui vasculite necrotizante, com poucos depósitos imunes ou ausência deles, acometendo pequenos vasos. Pode estar presente arterite necrotizante envolvendo pequenas e médias artérias. A glomerulonefrite necrotizante é muito comum (79\%-90\%), e a capilarite pulmonar ocorre freqüentemente (25\%-50\%), com hemorragias em $12 \%$ a $29 \%$ dos doentes. ${ }^{12,13} \mathrm{Na}$ poliangeíte microscópica ocorrem sintomas sistêmicos como febre, mialgia, perda de peso e artralgia. A púrpura palpável manifesta-se em 46\% dos pacientes na época da apresentação da doença, e cerca de $90 \%$ dos doentes têm Anca positivo no soro., ${ }^{3,-6}$

Podem ser observadas no quadro 1 as diferenças entre poliarterite nodosa e poliangeíte microscópica.

\subsubsection{Granulomatose de Wegener}

É doença multissistêmica rara, constituída por vasculite granulomatosa necrotizante. $\mathrm{O}$ trato respiratório superior e os rins são os locais de acometimento primário. Ocorre em torno da quarta e quinta décadas de vida, não há predileção por sexo, e indivíduos da cor branca são mais acometidos. ${ }^{2-4}$

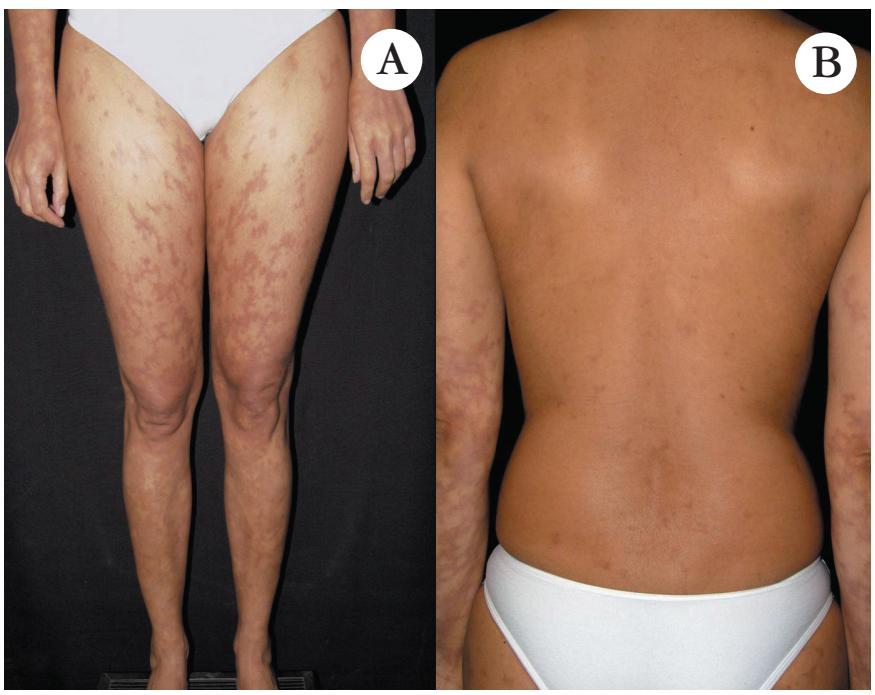

Figura 3: A e B - Livedo racemoso com predomínio nas extremidades 

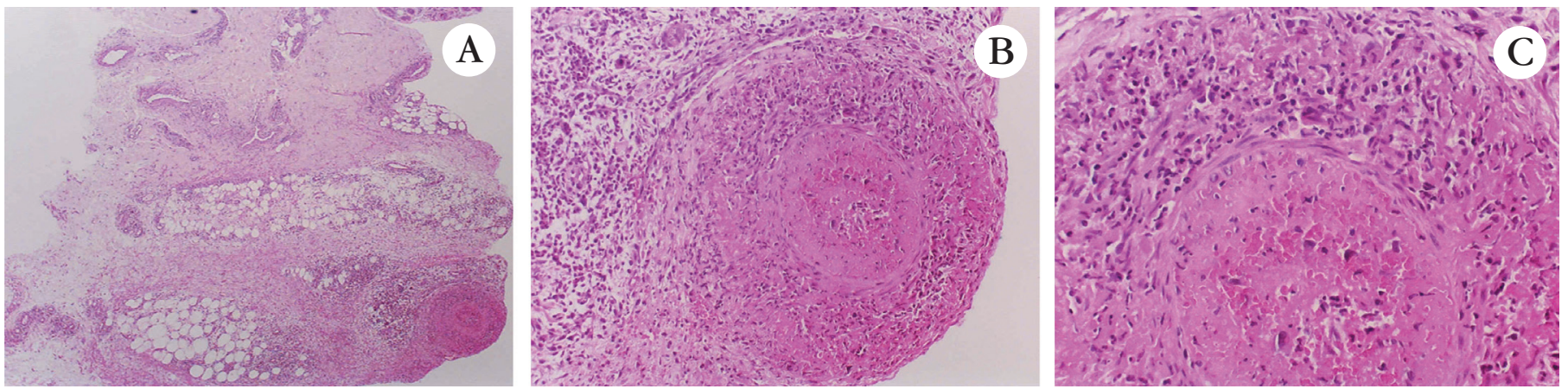

Figura 4: A, B e C - A - Comprometimento de artéria de septo da hipoderme.HE 100x; B - Permeação de todas as camadas de suas paredes por infiltrado inflamatório, além de alteração fibrinóide de suas paredes. HE 200x C - Infiltrado inflamatório misto que permeia as túnicas

da parede vascular. e trombose recente. HE 400x

Fadiga, mal-estar, mialgia, artralgia, anorexia e perda de peso são freqüentes. A doença pulmonar é comum (50-85\%) e se manifesta por tosse seca crônica, hemoptise entre moderada e grave, e insuficiência respiratória; aproximadamente um terço dos pacientes é assintomático. ${ }^{14,15}$ Pode haver pneumonite difusa aguda assim como síndrome hemorrágica alveolar associada. ${ }^{15,16}$ $\mathrm{O}$ acometimento do trato respiratório superior ocorre como sinusite crônica (50-80\%). Mais raramente ocorre perfuração septal e nariz em sela. Úlceras orais crônicas podem ser dolorosas ou não. ${ }^{15-17} \mathrm{O}$ envolvimento do ouvido pode ser evidenciado por obstrução do canal auditivo (otites) e perda de audição condutiva ou neurossensorial. A inflamação pode comprimir o VII par craniano (paralisia facial periférica). A graulomatose de Wegener (GW) pode afetar qualquer órgão, como pele, olhos, traquéia, sistema nervoso central, coração, mamas, próstata, trato gastrointestinal, vulva e colo do útero. ${ }^{3,4}$

Manifestações cutâneas ocorrem em 45\% dos casos e são polimorfas, podendo manifestar-se púrpura palpável, nódulos, ulcerações necróticas, vesículas, pústulas e lesões tipo pioderma gangrenoso. As alterações cutâneas raramente dominam o quadro clínico. ${ }^{17-19}$

A GW é entidade clinicopatológica, motivo pelo qual as manifestações clínicas devem ser complementadas com achados histológicos de vasculite necrotizante granulomatosa em algum dos órgãos afetados, principal- mente no tecido pulmonar. A vasculite granulomatosa no tecido renal é muito rara., ${ }^{3,4,19}$

O exame histopatológico caracteriza-se por infiltrados nodulares, como abscessos, com grande acúmulo de polimorfonucleares circundados por linfócitos, plasmócitos, histiócitos em paliçada, fibroblastos e células gigantes. ${ }^{19}$

Clinicamente, a tríade clássica - granuloma necrotizante do trato respiratório, vasculite necrotizante cutânea e glomerulonefrite - orienta o diagnóstico, mas essas alterações não necessariamente estarão presentes simultaneamente..$^{2-4}$

Os achados de exames laboratoriais, em geral, não são específicos, revelando enfermidade inflamatória sistêmica. ${ }^{14,20}$

Os critérios clínicos e histológicos são os propostos pelo Colégio Americano de Reumatologia, podendo constituir guia útil no diagnóstico da doença. ${ }^{2}$

Davies, em 1982, e Van der Woude, em 1985, demonstraram a presença de anticorpos contra o citoplasma de neutrófilos (Anca) no soro de pacientes com granulomatose de Wegener. ${ }^{21-23}$ Esses anticorpos são marcadores sorológicos da doença e têm especificidade de $99,3 \%$. Os que apresentam padrão citoplásmico (c- Anca) estão dirigidos contra a proteinase-3 (PR-3), serinaprotease com peso molecular de $29 \mathrm{kD}$, distribuída nos grânulos azurófilos dos lisossomos dos neutrófilos humanos. Os anticorpos com padrão perinuclear ( $\mathrm{p}$ - Anca)

QUADRO 1: Diferenças clínicas entre poliarterite nodosa e poliangeíte microscópica

\section{Característica clínica}

Microaneurismas na angiografia

Nefrite rapidamente progressiva

Hemorragia pulmonar

Hipertensão renovascular

Neuropatia periférica

Sorologia positiva para hepatite B

Sorologia positiva para Anca

Recidivas
Poliarterite nodosa

Poliangeíte microscópica

Sim

Não

Não

$\operatorname{Sim}(10-33 \%)$

$\operatorname{Sim}(50-80 \%)$

Incomum

Rara

Raras
Não

Sim

Sim

Não

Não

Não

Frequente

Frequentes

* Fonte adaptada: Crowson et al. ${ }^{90}$ 
estão dirigidos contra mieloperoxidase (MPO), catepsina $G$, lactoferrina, elastase e contra outros antígenos ainda não identificados., ${ }^{3,421-23}$

A clonagem da proteinase- 3 permitiu estabelecer alto grau de homologia com a mieloblastina, ao comparar sua seqüência molecular, o que sugere gene codificador comum. ${ }^{22,23}$

Em relação aos aspectos genéticos, existe associação entra a expressão de Anca em pacientes com granulomatose de Wegener e os genes de classe II do complexo principal de histocompatibilidade, de tal forma que a freqüência do HLA-DQw7 em caucasianos está significativamente aumentada para $53 \%$ contra $27 \%$ dos controles, sendo o risco relativo de 2,9\%. Aparentemente, o haplótipo DQw7 associado ao DR2 faz com que os Anca sejam persistentemente positivos. ${ }^{3,4}$

O diagnóstico diferencial deve estabelecer-se com poliarterite nodosa clássica, vasculite por hipersensibilidade, síndrome de Goodpasture, vasculite alérgica de Churg-Strauss, granulomatose sarcóide necrotizante e granulomatose linfomatóide. ${ }^{3.5}$

O tratamento nesses pacientes deve ser precoce, à base de corticosteróides e imunossupressores, especificamente ciclofosfamida, para evitar curso fatal da enfermidade já que, sem tratamento, $90 \%$ dos pacientes morrem antes de dois anos, devido à uremia ou insuficiência respiratória. ${ }^{3,4,18,24,25}$

\subsubsection{Síndrome de Churg-Strauss}

É inflamação granulomatosa rica em eosinófilos envolvendo o trato respiratório e vasculite necrotizante de vasos de médio e pequeno calibre associada com asma e eosinofilia. ${ }^{26}$ É doença própria da meia-idade, que acomete igualmente o sexo masculino e o feminino. ${ }^{1,27}$ São considerados fatores desencadeantes da síndrome de Churg-Strauss (SCS): vacinações, procedimentos de dessensibilização, uso dos inibidores dos leucotrienos (ainda controverso) e suspensão abrupta de corticosteróides. ${ }^{28}$

A doença se inicia, geralmente, com manifestações respiratórias de asma ou rinite, ${ }^{3,4}$ manifestações que podem preceder ou eventualmente ser simultâneas à vasculite. Os pulmões são quase sempre comprometidos, com infiltrados difusos ou nodulares, sem tendência à cavitação e que podem evoluir em surtos. ${ }^{28} \mathrm{O}$ quadro clínico é de asma, sem história pregressa de atopia, associada à rinite e sinusite. ${ }^{29}$ Neuropatia periférica é expressa como mononeurite multiplex, ocorrendo em $60 \%$ dos casos. ${ }^{30,31} \mathrm{O}$ trato digestivo é acometido em $60 \%$ dos casos, com dores abdominais, perfurações e obstruções intestinais e vasculites mesentéricas com diarréia e hemorragias digestivas. Podem surgir miocardites, pericardites e doença coronariana, sendo as lesões cardíacas a causa de óbito em $40 \%$ dos doentes. ${ }^{32-34}$

As manifestações cutâneas ocorrem em cerca de
50\% dos casos: púrpura palpável em 48\% dos casos, nódulos subcutâneos em 30\%, erupção maculopapulosa em $25 \%$, erupções urticariformes em $25 \%$ dos pacientes. ${ }^{29}$

O prognóstico da SCS é melhor do que o da PAN ou da $\mathrm{GW}^{4,30,32}$

A SCS apresenta três fases evolutivas distintas: 1a fase: rinite alérgica, polipose nasal e asma, persistindo por anos ou décadas; 2 a fase: pneumonia eosinofílica, gastroenterite e eosinofilia periférica, com recorrências freqüentes; e 3a fase: vasculite sistêmica com inflamação granulomatosa, ocorrendo em média três anos após manifestações iniciais, mas podendo manifestar-se até 30 anos depois. ${ }^{30}$

A avaliação laboratorial na SCS revela alterações semelhantes às observadas na GW. Contudo na SCS há eosinofilia proeminente $(>10 \% / \mathrm{ml})$ e Anca positivo em percentual que varia de $60 \%$ a $70 \%$ dos pacientes, com padrão p-Anca. ${ }^{20,29}$

O exame histopatológico da SCS caracteriza-se por infiltrado eosinofílico do tecido, formação de granulomas extravasculares no tecido cutâneo e órgãos internos, e vasculite necrotizante acometendo artérias e veias. O granuloma da SCS contém leucócitos polimorfonucleares necróticos, eosinófilos, intensa degeneração fibrinóide e das fibras colágenas, e proliferação de tecido de granulação.

\subsection{Vasculites induzidas por droga associada ao Anca}

Há fortes evidências da ocorrência de vasculite associada ao uso da hidralazina, propiltiouracil e derivados, minociclina, penicilamina, alopurinol ou sulfasalazina.3 Outras drogas relacionadas são: metimazol, fenitoína, tiazidas, cefotaxima e retinóides. ${ }^{3,35}$

As lesões dermatológicas comuns a esse grupo são placas e nódulos purpúricos acrais (face, mamas, extremidades e orelhas) e gangrena digital (Figura 5).
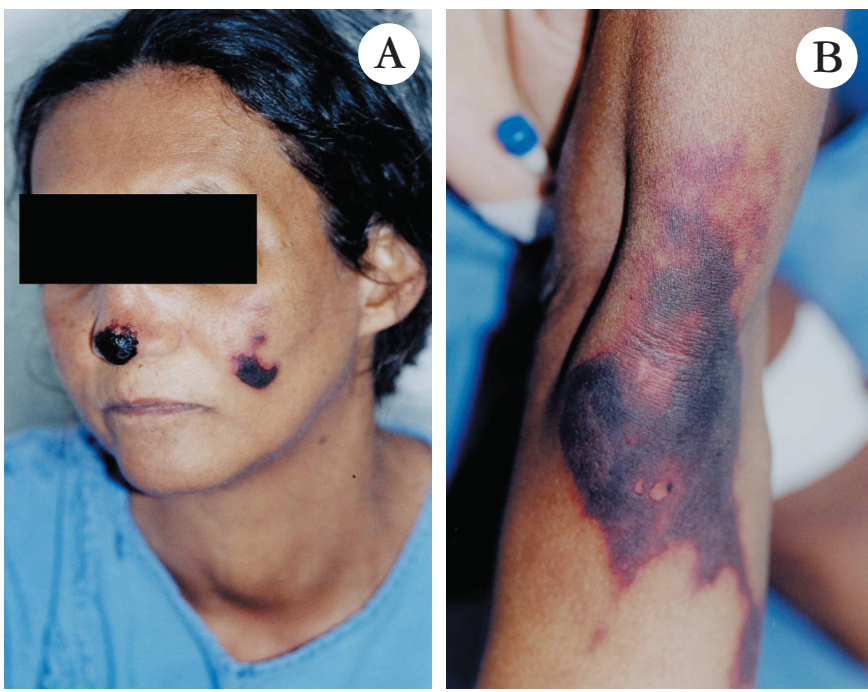

FIGURA 5: A e B: Placas purpúricas e necróticas acometendo ponta nasal e região malar (A) e extremidades (B) 
O exame anatomopatológico revela vasculite leucocitoclástica na derme superficial e profunda com IFD sem fluorescência específica. Geralmente ocorre associação com glomerulonefrite necrotizante e hemorragia pulmonar. ${ }^{36-38} \mathrm{~A}$ vasculite induzida por hidralazina associada ao Anca é com freqüência equivocadamente diagnosticada como lúpus induzido por droga. Diferenciase do lúpus por apresentar acometimento renal. Pode haver anticorpos anti-histonas e antiDNA dupla hélice. Não há associação ao fenótipo de acetilador lento e não há serosite. ${ }^{37,38}$

A vasculite induzida por minociclina associada ao Anca apresenta livedo reticular e/ou nódulos subcutâneos nas extremidades associados à febre e artralgia. A maioria dos pacientes apresenta p-Anca positivo ou anticorpos antimieloperoxidase. Os doentes geralmente não têm anticorpos anti-histona. ${ }^{39} \mathrm{~A}$ minociclina é conhecida por induzir reações imunes, como a doença do soro-símile, lúpus induzido por droga, hepatite auto-imune, pneumonite eosinofílica e vasculite. A maioria dos casos de vasculite induzida pela minociclina ocorre após dois anos de uso, principalmente em doentes tem tratamento de acne. Essa associação deve ser lembrada sobretudo nas vasculites em mulheres jovens que utilizam a droga e exibem manifestações clínicas auto-imunes. ${ }^{35,40-43}$

A vasculite de hipersensibilidade ao propiltiouracil (PTU) representa vasculite do tipo leucocitoclástica dos vasos dérmicos superficiais e profundos. Pode ocorrer com drogas antitireoideanas quimicamente relacionadas ao PTU. As manifestações variam desde febre e artralgia até síndrome pulmonar-renal. Esse tipo de vasculite é associado a dores articulares, febre, mal-estar, perda de peso, nefrite, hepatite, pericardite, que fazem parte das reações lúpus-símile induzidas pelo PTU. Esses achados podem ocorrer com lesões purpúricas e necróticas na pele, particularmente acrais e no pavilhão auricular, além de úlceras necróticas na cavidade oral e orofaringe. Após remoção do PTU ocorre resolução clínica da vasculite de hipersensibilidade, acompanhada de normalização dos exames laboratoriais. $^{36-38}$

De forma geral, as manifestações clínicas das vasculites dos pequenos vasos associadas ao Anca são: constitucionais: febre, perda de peso, anorexia, malestar; músculo-esqueléticas: mialgia, artralgia; da pele: púrpura palpável, urticária; dos rins: proteinúria, hematúria, insuficiência renal, glomerulonefrite necrotizante; do trato respiratório: dispnéia, tosse, hemoptise, infiltrados pulmonares, doença pulmonar intersticial, hemorragia pulmonar; do sistema nervoso: neuropatia periférica, especialmente mononeurite; do trato gastrointestinal: sangue nas fezes, aumento das enzimas hepáticas, diarréia, náusea, vômitos, dor abdominal.

\section{3 - VASCULITES ASSOCIADAS COM DOENÇAS AUTO-IMUNES E DO TECIDO CONECTIVO}

As vasculites podem estar associadas com doenças auto-imunes e do colágeno, como na artrite reumatóide (AR), no lúpus eritematoso sistêmico (LES), síndrome de Sjögren, Crest (calcinose, Raynaud, envolvimento esofágico, esclerodactilia, telangiectasia) e esclerodermia sistêmica progressiva.

A vasculite constitui manifestação incomum, porém importante, das doenças auto-imunes. É mais freqüentemente observada na AR, no LES, na esclerodermia sistêmica e na síndrome de Sjögren. ${ }^{44}$

A vasculite reumatóide (VR) acomete entre 5\% e 15\% dos doentes com artrite reumatóide. Costuma manifestar-se em doentes de meia-idade com AR que são tabagistas, possuem doença de longa data e altos títulos de fator reumatóide. A pele e os nervos são os tecidos mais freqüentemente acometidos, determinando gangrena periférica e mononeurite múltipla. ${ }^{45-51}$

No LES qualquer vaso pode ser acometido. O espectro clínico de manifestações dermatológicas inclui a púrpura palpável, urticária, microinfartos digitais e ulcerações profundas, sugestivas de vasculite sistêmica. A vasculite tipicamente ocorre durante os surtos de agudização, determinando pior prognóstico. ${ }^{44,52}$

Na síndrome de Sjögren a vasculite cutânea pode manifestar-se em $20 \%$ dos doentes sob a forma de púrpura palpável (Figura 6), equimoses ou urticária. Também se podem encontrar a presença do fenômeno de Raynaud e nódulos eritematosos nas coxas. ${ }^{53}$

$\mathrm{Na}$ esclerodermia sistêmica ou nos doentes com Crest, os pequenos vasos da pele são acometidos primariamente causando ulcerações e cicatrizes nas pontas dos dedos das mãos e dos pés. ${ }^{54}$

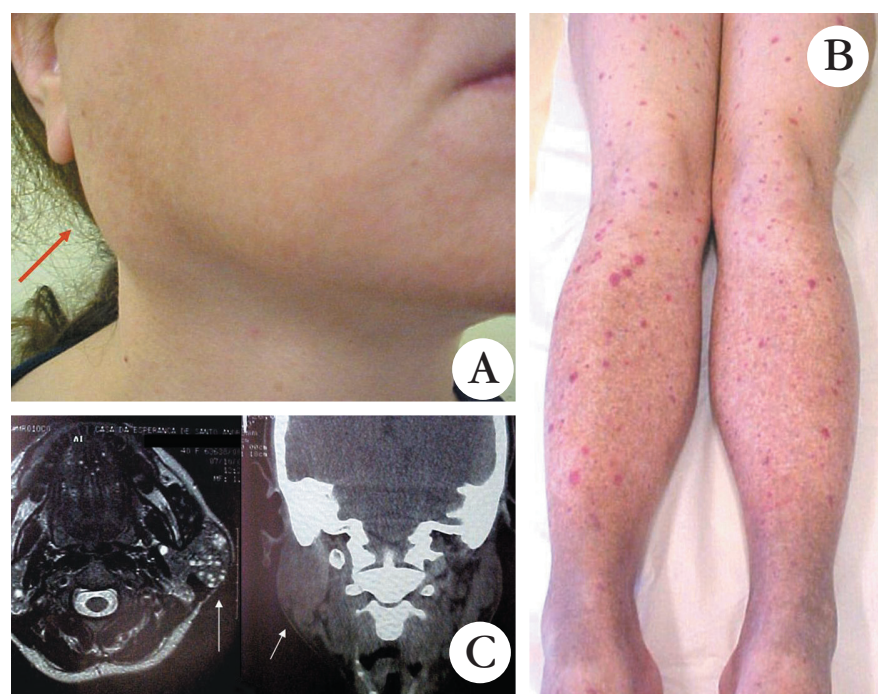

FIGURA 6: A - Aumento de volume na topografia de parótida direita B - Púrpura palpável nos membros inferiores C - Tomografia computadorizada de crânio e face evidenciando aumento das parótidas, principalmente à direita 


\section{4 - DERMATOSES NEUTROFÍLICAS COM DESOR- DENS VASCULARES ASSOCIADAS}

As dermatoses neutrofílicas (DN) constituem grupo heterogêneo de doenças unificadas pelos achados histopatológicos em comum: extenso infiltrado inflamatório dérmico neutrofílico e não infeccioso. Manifestações extracutâneas e doenças sistêmicas são freqüentemente associadas com as DN. A superposição das entidades também é observada. Historicamente, essas doenças têm sido classificadas baseando-se na presença ou ausência de vasculite nas lesões cutâneas:6, 55 (i) sem vasculite associada (1. síndrome de Sweet; 2. pioderma gangrenoso; 3. dermatite neutrofílica reumatóide; 4 . síndrome artrite-dermatite associada a doença inflamatória intestinal); (ii) com vasculite associada (doença de Behçet; 2 . erythema elevatum diutinum; 3. granuloma facial).

É difícil determinar se a agressão vascular é mecanismo patogênico primário, ou seja, dano mediado por imunocomplexos (vasculite primária), ou constitui ocorrência secundária ou epifenômeno (vasculite secundária). A presença de imunocomplexos dentro da parede vascular observada pela imunofluorescência direta é indicativo diagnóstico de vasculite primariamente mediada por imunocomplexos ou vasculite leucocitoclástica dos pequenos vasos. Entretanto, na ausência desses achados de IFD, não é possível excluir completamente a vasculite como processo primário. ${ }^{5,6,55}$

\subsection{Vasculites crônicas fibrosantes da pele}

Esse grupo é constituído por duas formas de vasculites cutâneas que caracteristicamente se resolvem com reação cutânea fibrosante: o erythema elevatum diutinum e o granuloma facial..$^{56-59}$

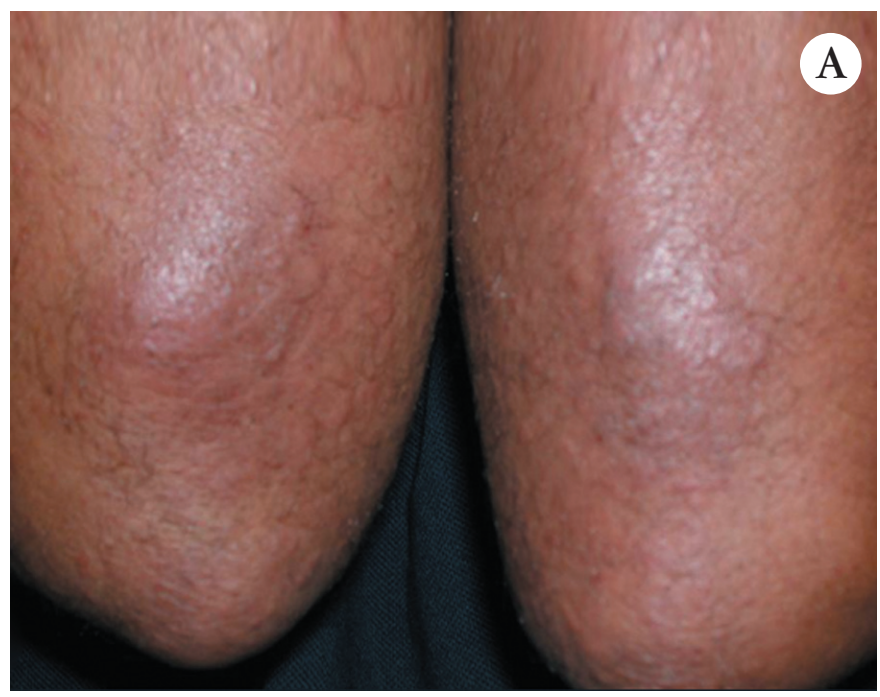

FIGURA 7: A - Placa papulosa e eritematosa na superfície extensora dos membros superiores

\subsubsection{Erythema elevatum diutinum}

Acomete mais mulheres, e o substrato anatomopatológico é a vasculite leucocitoclástica. Pode estar associado com anormalidades hematológicas, particularmente gamopatia monoclonal por IgA. Também tem sido associado ao HIV, HHV-6, leucemia mielóide, mielodisplasia, infecções crônicas, doença inflamatória intestinal ou ao pós-operatório de transplante hepático. Parece relacionar-se a estímulos infecciosos, particularmente estreptocócicos, pois a doença é exacerbada após infecções estreptocócicas e até mesmo após o uso do trombolítico estreptoquinase. Vários doentes têm doença inflamatória intestinal associada, e há relato de evolução para mieloma múltiplo tipo IgA..$^{58,60-64}$

As lesões cutâneas podem manifestar-se como pápulas, placas papulosas ou nódulos não purpúricos, de curso crônico, eritematosos ou por vezes de cor acastanhada. Preferencialmente ocorrem na superfície extensora das extremidades (Figura $7 \mathrm{~A}$ ), na pele sobre as articulações das mãos e joelhos, sendo essa distribuição extremamente característica. Também podem localizar-se nas nádegas e sobre o tendão do calcâneo. A face e o pavilhão auricular podem ser envolvidos, em geral poupando o tronco e as mucosas. A superfície costuma ser lisa, podendo haver discreta descamação sobre as lesões. Pode ocorrer nas lesões a presença de púrpura, bolha, crosta hemorrágica, ulceração, especialmente nas lesões muito edematosas. No curso da doença as lesões podem involuir espontaneamente, deixando áreas atróficas com hiper ou hipopigmentação. Cerca de $40 \%$ dos pacientes têm artralgia associada. O curso é crônico, por vezes ocorrendo involução. O clima frio parece agravar a doença. ${ }^{58,60-64}$

O exame histopatológico das lesões agudas evidencia vasculite leucocitoclástica, podendo haver eosinófilos na derme superior e média. Nas lesões crônicas são observados fibrose, proliferação capilar e infiltrado de macrófagos, plasmócitos e linfócitos. Depósito de colesterol intra e extracelular pode estar presente em lesões antigas (Figura 7 B, C, D).

Há boa resposta terapêutica à dapsona e sulfapiridina, e referências aos efeitos supressivos da niacinamida na atividade da doença. Formas localizadas podem ser tratadas com corticosteróide intralesional ou tópico de alta potência. ${ }^{57.58}$

\subsubsection{Granuloma facial}

É afecção incomum caracterizada pelo aparecimento de lesão ou lesões castanho-purpúricas na face. São placas papulosas ou nodosas, localizadas geralmente nas regiões de fronte, nariz ou boca. A superfície é lisa, podendo haver acentuação dos óstios foliculares. Raramente são acometidas outras áreas além da face (Figura 8 A e B). Existe uma variante que atinge a mucosa nasal, denominada fibrose angiocêntrica eosinofílica, que raramente coexiste com as lesões cutâneas faciais. Ocorre sobretudo em adultos. ${ }^{65-68}$ 

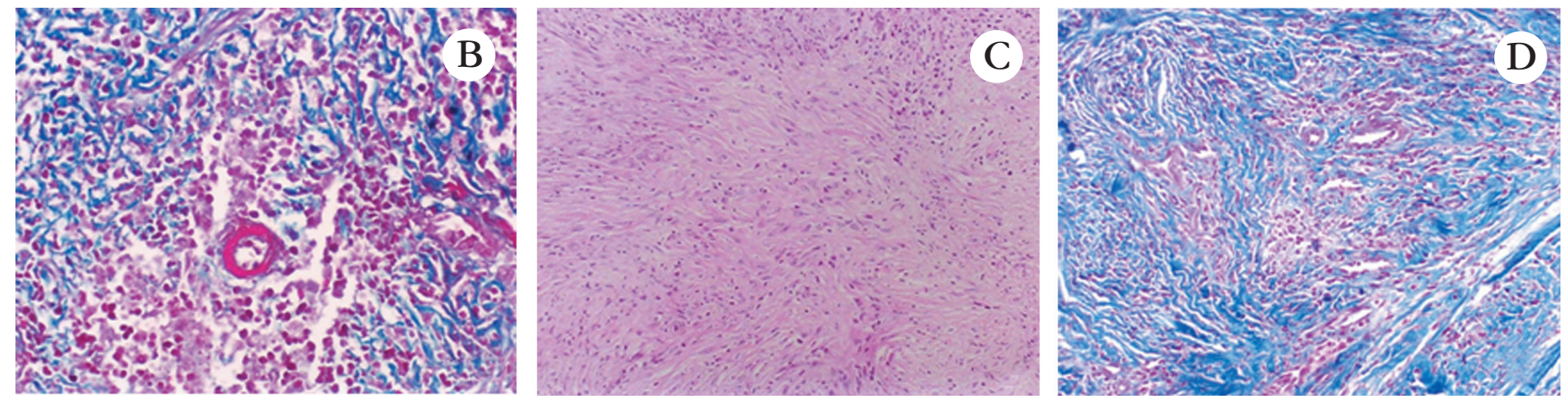

FIGURA 7: B - Pequeno vaso sangüíneo com alteração fibrinóide de sua parede envolvido por exsudato inflamatório que dissocia as fibras colágenas da derme (coloração pelo tricrômico de Masson) HE 200x; C - Fibrogênese dérmica de padrão estoriforme. HE 100x; D - Vasculite ainda em atividade e deposição de fibras colágenas com padrão estoriforme (coloração pelo tricrômico de Masson) HE 100x

O exame histopatológico revela vasculite leucocitoclástica, infiltrado com plasmócitos, linfócitos, histiócitos, neutrófilos e numerosos eosinófilos. Na IFD são observados depósitos de IgA, IgG, IgM e C3 nas paredes dos vasos, sugerindo participação de imunocomplexos na gênese da lesão (Figura $8 \mathrm{C}$ e D) ${ }^{66-8}$

O diagnóstico é clínico e histopatológico. São diagnósticos diferenciais os linfomas, pseudolinfomas, sarcoidose, sífilis, lúpus túmido, hanseníase, rosácea granulomatosa e erupção polimorfa à luz. As formas extrafaciais devem ser distinguidas do erythema elevathum diutinum..$^{56,65}$

São utilizados no tratamento corticosteróide intralesional, sulfona, antiinflamatórios não hormonais e clo- fazimina. Há relatos de bons resultados com laser. A criocirurgia também é efetiva, com a desvantagem de cicatrizes residuais. ${ }^{56,65}$

\subsection{Vasculite nodular}

A vasculite nodular (VN) acomete principalmente mulheres de meia-idade. As pernas são predominantemente afetadas, com lesões nodulares, particularmente nas regiões póstero-laterais. Podem surgir lesões nas coxas e braços. A resolução das lesões que não ulceram costuma ocorrer no prazo de duas a seis semanas, evoluindo com cicatriz e pouca atrofia. Os nódulos surgem em intervalos regulares, durante meses ou anos. A histopatologia pode demonstrar VCPV, e o acometimento do
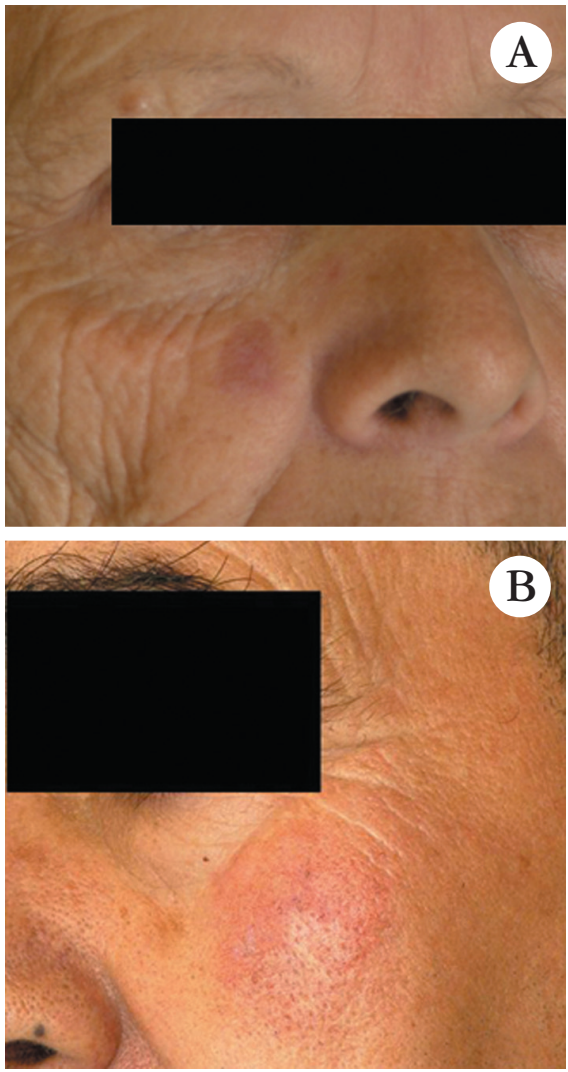

Figura 8: A e B - Placa eritêmato-infiltrada na região malar. A HE 100x - B HE 200x
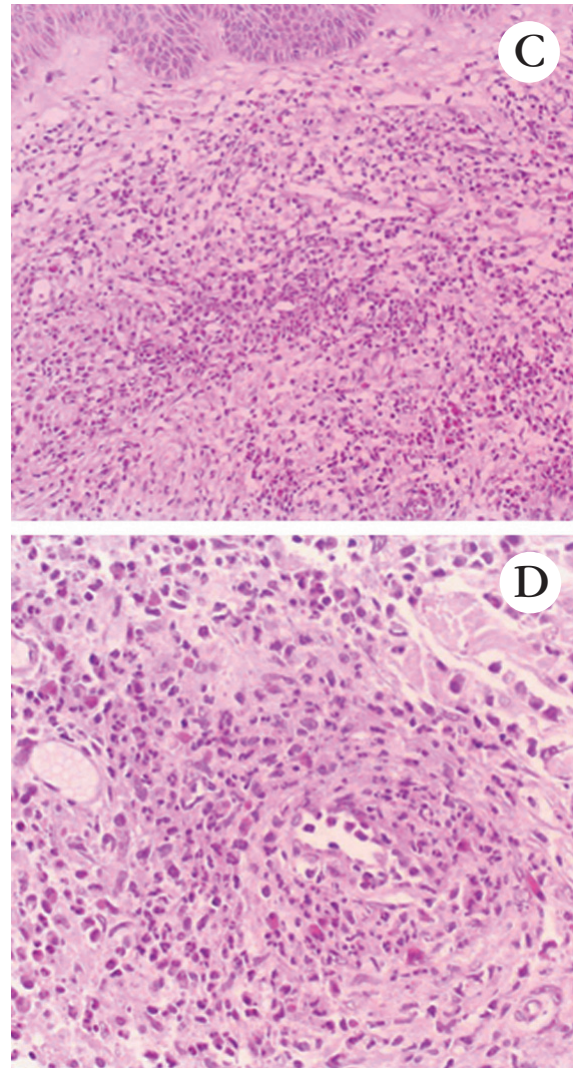

Figura 8: C Infiltrado inflamatório que envolve e agride os pequenos vasos dérmicos; ausência de agressão epidérmica pelo processo; D Pequeno vaso dérmico com suas paredes permeadas por infiltrado celular composto por neutrófilos, linfócitos e eosinófilos, notar figuras de leucocitoclasia na derme adjacente 
QUADRo 2: Sinopse do tratamento das vasculites de médios vasos

\begin{tabular}{|c|c|c|}
\hline $1^{\circ}$ passo: & \multicolumn{2}{|c|}{$\begin{array}{l}\text { exclusão de etiologia infecciosa, neoplásica ou inflamatória óbvia. A etiologia tratável } \\
\text { existe em } 50 \% \text { dos pacientes. }\end{array}$} \\
\hline $2^{\circ}$ passo: & \multicolumn{2}{|c|}{$\begin{array}{l}\text { exclusão de envolvimento sistêmico ou abordagem adequada. Presente (excluindo-se } \\
\text { artralgia) em } 20 \% \text { dos pacientes com manifestação cutânea. }\end{array}$} \\
\hline $3^{\circ}$ passo: & \multicolumn{2}{|c|}{ escolha terapêutica, individualizada abaixo. } \\
\hline \multirow[t]{4}{*}{ PAN clássica associada ao VHB } & $\mathbf{1}^{\mathrm{a}}$ linha & $\begin{array}{l}\text { Troca de plasma }+ \text { vidarabina }(+ \text { corticosteróide })^{\mathrm{B}} \text { ou troca de plasma }+ \\
\text { interferon } \alpha 2 \mathrm{~b}\left(+ \text { corticosteróide }{ }^{\mathrm{C}}\right.\end{array}$ \\
\hline & $2^{a}$ linha & $\begin{array}{l}\text { Lamivudine } ;{ }^{\mathrm{D}} \text { troca de plasma }+ \text { corticosteróide } ;{ }^{*}{ }^{\mathrm{B}} \text { troca de plasma }+ \\
\text { corticosteróide }^{*}+\text { ciclofosfamida }\end{array}$ \\
\hline & $3^{\text {a }}$ linha & IgIV \\
\hline & \multicolumn{2}{|c|}{ *Devido ao risco de replicação viral, deve ser usado para controle inicial por curto período. } \\
\hline $\begin{array}{l}\text { PAN clássica não associada } \\
\text { ao VHB }\end{array}$ & \multirow{2}{*}{\multicolumn{2}{|c|}{$\begin{array}{l}\text { Para os pacientes com doença grave (escore de cinco fatores } \geq 2 \text { ): ciclofosfamida }+ \\
\text { corticosteróidesB } \\
\text { A troca de plasma é ineficaz }\end{array}$}} \\
\hline & & \\
\hline \multirow[t]{2}{*}{ PAN cutânea } & $\begin{array}{l}1^{a} \text { linha } \\
2^{a} \text { linha }\end{array}$ & $\begin{array}{l}\text { Aines } ;^{\mathrm{D}} \text { AAS } ;{ }^{\mathrm{D}} \text { penicilina }(\text { se associada à estreptococcia })^{\mathrm{D}} \\
\text { Corticosteróides } ;{ }^{\mathrm{C}} \text { IgIV; metotrexate }(7,5-15 \mathrm{mg} / \text { semana, por } 6 \text { a } 12 \text { meses }){ }^{\mathrm{E}} \\
\text { IgIVE }\end{array}$ \\
\hline & $3^{\mathrm{a}}$ linha & $\begin{array}{l}\text { Pentoxifilina }(400 \mathrm{mg} / \mathrm{VO} / 3 \mathrm{x} \text { dia); sulfapiridina (quando associada a doença } \\
\text { intestinal inflamatória) } \\
\text { Para formas de apresentação com necrose acral: prostaglandina } \\
\text { (PGI2 50 } \mathrm{g} \text { EV/dia) e nifedipina }(60 \mathrm{mg} / \mathrm{dia})\end{array}$ \\
\hline \multirow{3}{*}{$\begin{array}{l}\text { Síndrome de Churg-Strauss } \\
\text { (SCS) e poliangeíte } \\
\text { microscópica (PAM) }\end{array}$} & & Postula-se tratamento similar aos casos de PAN clássica sem VHB \\
\hline & & $\begin{array}{l}\text { Para pacientes com doença grave [escore de } 5 \text { fatores }(\mathrm{ECF}) \geq 2 \text { ]: } \\
\text { ciclofosfamida }+ \text { corticosteróides }\end{array}$ \\
\hline & & $\begin{array}{l}\text { Para pacientes com escore de } 5 \text { fatores }(\mathrm{ECF})<2 \text { : corticosteróidesB } \\
\text { Considerar agentes citotóxicos se houver: neuropatia, GN refratária aos CE, } \\
\text { doença miocárdica, isquemia GI grave ou acometimento do SNC }\end{array}$ \\
\hline \multirow{3}{*}{$\begin{array}{l}\text { Granulomatose de Wegener (GW) } \\
\text { Indução de remissão }\end{array}$} & $\mathbf{1}^{\mathrm{a}}$ linha & Ciclofosfamida + corticosteróide $^{\mathrm{B}}$ \\
\hline & $2^{a}$ linha & Metotrexate + corticosteróide $^{\text {в }}$ \\
\hline & $3^{a}$ linha & Micofenolato mofetilC ou IgIV \\
\hline \multirow{3}{*}{$\begin{array}{l}\text { Granulomatose de Wegener (GW) } \\
\text { Manutenção }\end{array}$} & $1^{a}$ linha & Azatioprina + corticosteróide $^{\mathrm{A}}$ \\
\hline & $2^{a}$ linha & Ciclofosfamida + corticosteróide $^{\mathrm{B}}$ \\
\hline & $3^{a}$ linha & Micofenolato mofetil $^{\mathrm{C}}$ \\
\hline \multicolumn{3}{|l|}{ Granulomatose de Wegener (GW) } \\
\hline Recidiva & $\begin{array}{l}1^{\mathrm{a}} \text { linha } \\
2^{\mathrm{a}} \text { linha }\end{array}$ & $\begin{array}{l}\text { Ciclofosfamida }+ \text { corticosteróide }^{\mathrm{C}} \\
\text { IgIV }^{\mathrm{B}}\end{array}$ \\
\hline
\end{tabular}

AAS (ácido acetilsalicílico); Aines (antiinflamatórios não esteroidais); CE (corticosteróides); IgIV (imunoglobulina intravenosa); GN (glomerulonefrite); VHB (vírus da hepatite B); PAN (poliarterite nodosa); SNC (sistema nervoso central). Graus de recomendação: A (Estudo duplo-cego, randomizado); B (Estudo clínico com mais de 20 doentes, contudo ausência de controles adequados); C (Estudo clínico com menos que 20 doentes, relatos de casos com casuística superior a 20 doentes ou análise retrospectiva de dados); D (Séries com cinco ou menos doentes); E (Casos isolados).

Fonte adaptada: Fiorentino. ${ }^{3}$ 
tecido celular subcutâneo pode apresentar-se como paniculite. Classicamente são denominados eritemas indurados de Bazin os casos de vasculite nodular que ocorrem como manifestação tipo tubercúlide. Nessas circunstâncias, vários autores têm isolado fragmentos do DNA do $M$. tuberculosis através da análise tecidual destas lesões com a técnica da reação em cadeia da polimerase (PCR). ${ }^{7,8,69,70}$

Outras condições que podem ser associadas a vasculites cutâneas de pequenos vasos são síndrome de Sweet, pioderma gangrenoso, doença de Behcet, picadas de artrópodes, púrpura hipergamaglobulinêmica de Waldenström e doenças inflamatórias intestinais, que não pertencem ao escopo desta revisão e podem ser encontradas em literatura específica. ${ }^{69,71-73}$

\section{5 - VASCULITES DOS GRANDES VASOS}

São representadas pela arterite de células gigantes (arterite temporal) e arterite de Takayasu.

\subsection{Arterite de células gigantes (arterite temporal)}

O envolvimento das artérias de médio ou grande calibre da região temporal de forma uni ou bilateral constitui a forma mais comum de arterite de células gigantes. Mulheres caucasianas idosas são as mais afetadas. Anemia, VHS elevado, febre, cefaléia e polimialgia reumática são manifestações freqüentemente associadas. A lesão cutânea clássica é ulceração no couro cabeludo e o espessamento da artéria temporal. Quando presente, a arterite retiniana pode determinar cegueira. A histopatologia revela panarterite com células gigantes multinucleadas. ${ }^{74.85}$ Os critérios para o diagnóstico da arterite de células gigantes são os preconizados pelo Colégio Americano de Reumatologia. ${ }^{2}$

\subsection{Arterite de Takayasu}

Trata-se de arterite crônica que afeta a aorta e seus principais ramos. As manifestações sistêmicas podem ser extensas, dependendo da localização e da gravidade do leito vascular acometido pela doença. As manifestações dermatológicas incluem a púrpura palpável, úlceras ou lesões pioderma gangrenoso-símile. Arterite granulomatosa com estenose da artéria e fibrose é observada no exame anatomopatológico. O uso de corticosteróide sistêmico e de imunossupressores pode ser freqüentemente necessário, bem como intervenção cirúrgica.86-90 Os critérios diagnósticos da arterite de Takayasu são os preconizados pelo Colégio Americano de Reumatologia. ${ }^{1,2}$

\section{CONSIDERAÇÕES FINAIS}

As vasculites de médios e grandes vasos constituem desafio tanto para diagnóstico quanto terapêutica. Conceitos, classificações e técnicas diagnósticas estão em constante evolução. É importante que o dermatologista conheça as várias apresentações e sinais clínicos das vasculites, procurando reduzir a morbidade e mortalidade através de diagnóstico precoce e tratamento adequado, cuja sinopse pode ser consultada no quadro 2 . 


\section{REFERÊNCIAS}

1. Jennette JC, Falk RJ, Andrassy K, Bacon PA, Churg J, Gross WL, et al. Nomenclature of systemic vasculitides. Proposal of an international consensus conference. Arthritis Rheum. 1994;37:187-92.

2. Hunder GG, Arend WP, Bloch DA, Calabrese LH, Fauci AS, Fries JF et al. The American College of Rheumatology 1990 criteria for the classification of vasculitis. Arthritis Rheum. 1990;33:1065-136.

3. Fiorentino DF. Cutaneous vasculites. J Am Acad Dermatol. 2003;48:311-40.

4. Lotti T, Ghersetich I, Comacchi C, Jorizzo JL. Cutaneous small-vessel vasculitis. J Am Acad Dermatol. 1998;39:667-87.

5. Carlson JA, Ng BT, Chen KR. Cutaneous vasculitis update: diagnostic criteria, classification, epidemiology, etiology, pathogenesis, evaluation and prognosis. Am J Dermatopathol. 2005;27:504-28.

6. Carlson JA, Chen KR. Cutaneous vasculitis update: small vessel neutrophilic vasculitis syndromes. Am J Dermatopathol. 2006;28:486-506.

7. Lotti TM, Comacchi C, Ghersetich I. Cutaneous necrotizing vasculitis. Int J Dermatol 1996;35:457-74.

8. Comacchi C, Ghersetich I, Lotti T. Vasculite necrotizzante cutanea. G Ital Dermatol Venereol. 1998;133:23-49.

9. Provost TT, Kater L. Guidelines for the clinical application of immunologic laboratory investigations. In: Kater L, Baart de la Faille H, editors. Multi-systemic autoimmune diseases: an integrated approach. Amsterdam: Elsevier; 1995. p.61-84.

10. Callen JP, Kallenberg CGM. The vasculitides: relationship of cutaneous vasculitis to systemic disease. In: Kater L, Baart de la Faille H, editors. Multi-systemic auto-immune diseases: an integrated approach. Amsterdam: Elsevier; 1995. p.267-97.

11. Savige J, Davies D, Falk RJ, Jennette JC, Wiik A. Antineutrophil cytoplasmic antibodies and associated diseases: a review of the clinical and laboratory features. Kidney Int. 2000;57:846-62.

12. Niles JL, Bottinger EP, Saurina GR, Kelly KJ, Pan G, Collins $\mathrm{AB}$, et al. The syndrome of lung hemorrhage and nephritis is usually an ANCA-associated condition. Arch Intern Med. 1996;156:440-5.

13. Guillevin L, Lhote F. Treatment of polyarteritis nodosa and microscopic polyangitis. Arthritis Rheum. 1998;41:2100-5.

14. Yi ES, Colby TV. Wegener's granulomatosis. Semin Diagn Pathol. 2001;18:34-46.

15. Hoffman GS, Kerr GS, Leavitt RY, Hallahan CW, Lebovics RS, Travis WD, et al. Wegener granulomatosis: an analysis of 158 patients. Ann Intern Med. 1992;116:488-98.

16. Lie JT. Wegener's granulomatosis: histological documentation of common and uncommon manifestations in 216 patients. Vasa. 1997;26:261-70.

17. Lehmann H, Kiefer B. Clinical manifestations of Wegener's granulomatosis. APMIS Suppl. 1990;19:19-20.

18. Frances C, Du LT, Piette JC, Saada V, Boisnic S, Wechsler B, et al. Wegener's granulomatosis. Dermatological manifestations in 75 cases with clinicopathologic correlation. Arch Dermatol. 1994;130:861-7.

19. Barksdale S, Hallahan C, Kerr G, Fauci A, Stern J, Travis W. Cutaneous pathology in Wegener's granulomatosis. Am J Surg Pathol. 1995;19:161-72.

20. Stegeman CA, Kallenberg CG. Clinical aspects of primary vasculitis. Springer Semin Immunopathol. 2001;23:231-51.

21. Savige JA, Davies DJ. Anti-neutrophil cytoplasm antibodies (ANCA). Aust N Z J Med. 1990;20:271-4.

22. Savige JA, Yeung SP, Gallicchio M, Davies DJ. Two ELISAs to detect anti-neutrophil cytoplasm antibodies (ANCA) in various vasculitides. Pathology 1989;21:282-7.

23. Wiik A, van der Woude F. Anti-neutrophil cytoplasmic antibodies (ANCA): a historic review. APMIS Suppl. 1989; 6:7.

24. Kallenberg CG, Heeringa P, Stegeman CA. Mechanisms of Disease: pathogenesis and treatment of ANCA-associated vasculitides. Nat Clin Pract Rheumatol. 2006;2:661-70.

25. Fridlich R, David A, Aviram I. Membrane proteinase 3 and its interactions within microdomains of neutrophil membranes. J Cell Biochem. 2006;99:117-25.

26. Selamet U, Kovaliv YB, Savage CO, Harper L. ANCA-associated vasculitis: new options beyond steroids and cytotoxic drugs. Expert Opin Investig Drugs. 2007;16:689-703.

27. Fauci AS, Haynes B, Katz P. The spectrum of vasculitis: clinical, pathologic, immunologic and therapeutic considerations. Ann Intern Med. 1978;89:660-76.

28. Churg J, Strauss L. Allergic granulomatosis, allergic angiitis and periarteritis nodosa. Am J Pathol. 1951;27:277-301.

29. Lhote F, Cohen P, Guillevin L. Polyarteritis nodosa, microscopic polyangiitis and Churg-Strauss syndrome. Lupus. 1998; 7:238-58.

30. Lanham JG, Elkon KB, Pusey CD, Hughes GR. Systemic vasculitis with asthma and eosinophilia: a clinical approach to the Churg-Strauss syndrome. Medicine (Baltimore). 1984;63:65-81.

31. Guillevin L, Cohen P, Gayraud M, Lhote F, Jarrousse B, Casassus P. Churg-Strauss syndrome. Clinical study and long-term follow-up of 96 patients. Medicine (Baltimore) 1999; 78:26-37.

32. Lhote F, Guillevin L. Polyarteritis nodosa, microscopic polyangiitis, and Churg-Strauss syndrome: clinical aspects and treatment. Rheum Dis Clin North Am. 1995;21:911-47.

33. Davis MD, Daoud MS, McEvoy MT, Su WP. Cutaneous manifestations of Churg-Strauss syndrome: a clinicopathologic correlation. J Am Acad Dermatol. 1997;37:199-203.

34. Churg A. Recent advances in the diagnosis of ChurgStrauss syndrome. Mod Pathol. 2001;14:1284-93.

35. Choi HK, Merkel PA, Walker AM, Niles JL. Drug-associated antineutrophil cytoplasmic antibody-positive vasculitis: prevalence among patients with high titers of antimyeloperoxidase antibodies. Arthritis Rheum. 2000; 43:405-13.

36. Dolman KM, Gans RO, Vervaat TJ, Zevenbergen G, Maingay D, Nikkels RE, et al. Vasculitis and antineutrophil cytoplasmic autoantibodies associated with propylth iouracil therapy. Lancet. 1993;342:651-2.

37. Merkel PA. Drugs associated with vasculitis. Curr Opin Rheumatol. 1998;10:45-50.

38. Chastain MA, Russo GG, Boh EE, Chastain JB, Falabella A, Millikan LE. Propylthiouracil hypersensitivity: report of two patients with vasculitis and review of the literature. J Am Acad Dermatol. 1999; 41:757-64.

39. Schaffer JV, Davidson DM, McNiff JM, Bolognia JL. Perinuclear antineutrophilic cytoplasmic antibody-positive cutaneous polyarteritis nodosa associated with minocycline therapy for acne vulgaris. J Am Acad Dermatol. 2001;44:198-206.

40. Schrodt BJ, Kulp-Shorten CL, Callen JP. Necrotizing 
vasculitis of the skin and uterine cervix associated with minocycline therapy for acne vulgaris. South Med J. 1999;92:502-4.

41. Schrodt BJ, Callen JP. Polyarteritis nodosa attributable to minocycline treatment for acne vulgaris. Pediatrics. 1999; 103:503-4.

42. Elkayam O, Yaron M, Caspi D. Minocycline induced arthritis associated with fever, livedo reticularis, and pANCA. Ann Rheum Dis. 1996;55:769-71.

43. Elkayam O, Levartovsky D, Brautbar C, Yaron M, Burke M, Vardinon $\mathrm{N}$, et al. Clinical and immunological study of 7 patients with minocycline-induced autoimmune phenomena. Am J Med. 1998;105:484-7.

44. Hautmann G, Campanile G, Lotti TM. The many faces of cutaneous vasculitis. Clin Dermatol. 1999;17:515-31.

45. Danning CL, Illei GG, Boumpas DT. Vasculitis associated with primary rheumatologic diseases. Curr Opin Rheumatol. 1998;10:58-65.

46. Watts R, Carruthers D, Symmons D, Scott D. The incidence of rheumatoid vasculitis in the Norwich Health Authority. Br J Rheumatol. 1994;33:832-3.

47. Voskuyl A, Zwinderman A, Westeedt M, Vandenbroucke $\mathrm{J}$, Breedveld F, Hazes J. The mortality of rheumatoid vasculitis compared with rheumatoid arthritis. Arthritis Rheum. 1996;39:266-71.

48. Voskuyl A, Zwinderman A, Westedt M, Vandenbroucke J, Breedveld F, Hazes J. Factors associated with the development of vasculitis in rheumatoid arthritis: results of a casecontrol study. Ann Rheum Dis. 1996;55:190-2.

49. Bywaters E. A variant of rheumatoid arthritis characterized by digital pad nodules and palmar fasciitis, closely resembling palidromic rheumatism. Ann Rheum Dis. 1949;8:2-30.

50. Bywaters E, Scott J. The natural history of vascular lesions in rheumatoid arthritis. J Chronic Dis. 1963;16:905-14.

51. Breedveld FC. Vasculitis associated with connective tissue disease. Baillieres Clin Rheumatol. 1997;11:315-34.

52. Kerr G, Hoffman G. Systemic lupus erythematosus and the cardiovascular system: vasculitis. In: Lahita R, editor. Systemic lupus erythematosus. 2nd ed. New York: Churchill Livingstone;1992. p.719-29.

53. Yamamoto T, Yokoyama A. Hypergammaglobulinemic purpura associated with Sjogrens syndrome and chronic C type hepatitis. J Dermatol. 1997;24:7-11.

54. Hunder G. Vasculitis: diagnosis and therapy. Am J Med. 1996;100(Suppl):37S-45S.

55. Carlson JA, Chen KR. Cutaneous vasculitis update: neutrophilic muscular vessel and eosinophilic, granulomatous, and lymphocytic vasculitis syndromes. Am J Dermatopathol. 2007;29:32-43.

56. Carlson JA, LeBoit PE. Localized chronic fibrosing vasculitis of theskin: an inflammatory reaction that occurs in settings other than erythema elevatum diutinum and granuloma faciale. Am J Surg Pathol.1997;21:698-705.

57. Sangueza OP, Pilcher B, Martin Sangueza J. Erythema elevatum diutinum: a clinicopathological study of eight cases. Am J Dermatopathol.1997;19:214-222.

58. Dowlati B, Firooz A, Dowlati Y. Granuloma faciale: successful treatment of nine cases with a combination of cryotherapy and intralesional corticosteroid injection. Int $\mathrm{J}$ Dermatol.1997;36:548-551.

59. Ortonne N, Wechsler J, Bagot M, et al. Granuloma faciale: a clinicopathologic study of 66 patients. J Am Acad Dermatol. 2005;53:1002-1009.

60. Woody CM, Lane JE, Davis LS. Erythema elevatum diutinum in the setting of connective tissue disease and chronic bacterial infection. J Clin Rheumatol. 2005; 11:98-104.

61. Wahl CE, Bouldin MB, Gibson LE. Erythema elevatum diutinum: clinical, histopathologic, and immunohistochemical characteristics of six patients. Am J Dermatopathol. 2005;27:397-400.

62. LeBoit PE, Cockerell CJ. Nodular lesions of erythema elevatum diutinum in patients infected with the human immunodeficiency virus. J Am Acad Dermatol. 1993; 28:919-22.

63. Yiannias JA, el-Azhary RA, Gibson LE. Erythema elevatum diutinum: a clinical and histopathologic study of 13 patients. J Am Acad Dermatol. 1992;26:38-44.

64. Ayoub N, Charuel JL, Diemert MC, Barete S, André M, Fermand JP, et al. Antineutrophil cytoplasmic antibodies of IgA class in neutrophilic dermatoses with emphasis on erythema elevatum diutinum. Arch Dermatol. 2004; 140:931-6.

65. Radin DA, Mehregan DR. Granuloma faciale: distribution of the lesions and review of the literature. Cutis 2003;72:213-9.

66. LeBoit PE. Granuloma faciale: a diagnosis deserving of dignity. Am J Dermatopathol. 2002;24:440-3.

67. Zirwas MJ, Abell E, Ruben A, Silverman AR, Wolff J, Deng JS. Immunofluorescence findings in granuloma faciale: report of two cases. J Cutan Pathol. 2003;30:314-7.

68. Nieboer C, Kalsbeek GL. Immunofluorescence studies in granuloma eosinophilicum faciale. J Cutan Pathol 1978;5:68-75.

69. Kwok CY, Goh CL, Ong BH. Retrospective study of the epidemiology of nodular vasculitis followed up in the National Skin Centre, Singapore. Clin Exp Dermatol. 1997;22:17-9.

70. Campanile G, Lotti T. Clinical aspects of cutaneous necrotizing vasculitis. Int Angiol. 1995;14:151-61.

71. Requena L, Sanchez Yus E. Panniculitis. Part II. Mostly lobular panniculitis. J Am Acad Dermatol. 2001;45:325-61.

72. Parish WE, Rhodes EL. Bacterial antigens and aggregated gamma globulin in the lesions of nodular vasculitis. $\mathrm{Br} \mathrm{J}$ Dermatol. 1967;79:131-47.

73. Schneider JW, Jordaan HF. The histopathologic spectrum of erythema induratum of Bazin. Am J Dermatopathol 1997; 19:323-33.

74. Currey J. Scalp necrosis in giant cell arteritis and review of the literature. Br J Rheumatol. 1997;36:814-16.

75. Weidner N. Giant-cell vasculitides. Semin Diagn Pathol. 2001;18:24-33.

76. Calamia KT, Hunder GG. Clinical manifestations of giant cell (temporal) arteritis. Clin Rheum Dis. 1980;6:389-403.

77. Hamidou MA, Moreau A, Toquet C, et al. Temporal arteritis associated with systemic necrotizing vasculitis J Rheumatol. 2003;30:2165-9.

78. Genereau T, Lortholary O, Pottier MA, et al. Temporal artery biopsy: a diagnostic tool for systemic necrotizing vasculitis. French Vasculitis Study Group. Arthritis Rheum. 1999; 42:2674-81.

79. Rivers SP, Baur GM, Inahara T, Porter JM. Arm ischemia secondary to giant cell arteritis. Am J Surg. 1982;143:554-8

80. Weyand CM, Ma-Krupa W, Goronzy JJ. Immunopathways 
in giant cell arteritis and polymyalgia rheumatica. Autoimmun Rev. 2004;3:46-53.

81. Cantini F, Niccoli L, Storri L, Nannini C, Olivieri I, Padula A, et al. Are polymyalgia rheumatica and giant cell arteritis the same disease? Semin Arthritis Rheum. 2004;33:294-301.

82. Baum EW, Sams WM, Jr., Payne RR. Giant cell arteritis: a systemic disease with rare cutaneous manifestations. J Am Acad Dermatol. 1982;6:1081-8.

83. Campbell FA, Clark C, Holmes S. Scalp necrosis in temporal arteritis. Clin Exp Dermatol. 2003;28:488-90.

84. Matsushima M, Yamanaka K, Mori H, et al. Bilateral scalp necrosis with giant cell arteritis. J Dermatol. 2003;30:210-5.

85. Corcoran GM, Prayson RA, Herzog KM. The significance of perivascular inflammation in the absence of arteritis in temporal artery biopsy specimens. Am J Clin Pathol. 2001;115:342-7.

86. Johnston SL, Lock RJ, Gompels MM. Takayasu arteritis: a review. J Clin Pathol. 2002;55:481-6.

87. Ujiie H, Sawamura D, Yokota K, Nishie W, Shichinohe R, Shimizu H. Pyoderma gangrenosum associated with Takayasu's arteritis. Clin Exp Dermatol. 2004;29:357-9.
88. Pascual-López M, Hernández-Núñez A, Aragüés-Montañés M, Daudén E, Fraga J, García-Díez A. Takayasu's disease with cutaneous involvement. Dermatology. 2004;208:10-5.

89. Skaria AM, Ruffieux P, Piletta P, Chavaz P, Saurat JH, Borradori L. Takayasu arteritis and cutaneous necrotizing vasculitis. Dermatology. 2000;200:139-43.

90. Crowson AN, Mihm MC Jr, Magro CM. Cutaneous vasculitis: a review. J Cutan Pathol. 2003;30:161-73.

ENDEREÇO PARA CORRESPONDÊNCIA / MAILING ADDRESS:

Paulo Ricardo Criado

Divisão de Clínica Dermatológica - ICHC

Avenida Doutor Enéas Carvalbo de Aguiar, 255-3 Andar

05403000 - São Paulo - SP

Tel./fax: 55(11) 3069-8001 e 55(11) 3088-9145

E-mail: prcriado@uol.com.br 